\title{
Coarctation Long-term Assessment (COALA): Significance of arterial hypertension in a cohort of 404 patients up to 27 years after surgical repair of isolated coarctation of the aorta, even in the absence of restenosis and prosthetic material
}

Alfred Hager, MD, ${ }^{\text {a }}$ Simone Kanz, MD, ${ }^{\text {a }}$ Harald Kaemmerer, MD, VMD, FESC, ${ }^{\text {a }}$ Christian Schreiber, MD, ${ }^{\text {b }}$ and John Hess, MD, FESC ${ }^{\mathrm{a}}$

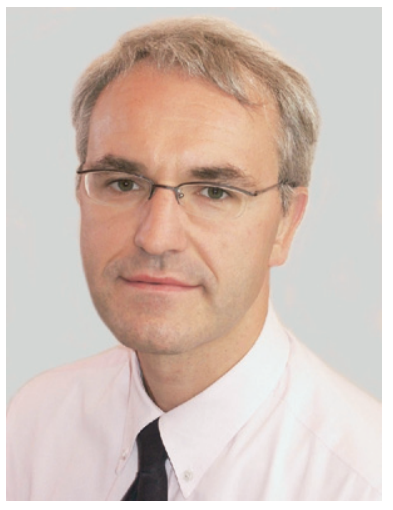

Dr Hager

$\S$ Supplemental material is available online.

From the Departments of Pediatric Cardiology and Congenital Heart Disease ${ }^{\mathrm{a}}$ and Cardiovascular Surgery, ${ }^{\mathrm{b}}$ Deutsches Herzzentrum München, Technische Universität München, Munich, Germany.

Presented in part at the 24th Congress of the European Society of Cardiology, Vienna, Austria, August 30-September 3, 2003, and at the 53rd Scientific Session of the American College of Cardiology, New Orleans, La, March 7-10, 2004.

Supported by Herzkind e.V., Braunschweig, Germany (www.herzkind.de).

Received for publication Jan 23, 2007; revisions received March 22, 2007; accepted for publication April 26, 2007.

Address for reprints: Alfred Hager, MD, Department of Pediatric Cardiology and Congenital Heart Disease, Deutsches Herzzentrum München, Technische Universität München, Lazarettstr. 36, D-80636 München, Germany (E-mail: a-hager@web.de).

J Thorac Cardiovasc Surg 2007;134:738-45

$0022-5223 / \$ 32.00$

Copyright (๑) 2007 by The American Association for Thoracic Surgery

doi:10.1016/j.jtcvs.2007.04.027
Objective: Recent studies have demonstrated that there is a loss of aortic compliance in patients after coarctation repair. The clinical effect of this and other mechanisms apart from restenosis on the rate of arterial hypertension is unknown.

Methods: From 1974 through 2000, 404 patients born before January 1, 1985, underwent surgical intervention for isolated aortic coarctation. From those 382 who are still alive, 273 patients aged 16 to 73 years (1-27 years after surgical intervention) underwent a structured clinical investigation according to a prospective protocol, including blood pressure measurement at all limbs, ambulatory blood pressure measurement, and symptom-limited exercise testing.

Results: Sixty-seven (25\%) patients were already taking antihypertensive drugs, and another $63(23 \%)$ patients had an increased ambulatory blood pressure. Still another $26(10 \%)$ patients had a blood pressure during exercise exceeding 2 standard deviations of reference values. Only 117 (43\%) patients had a normal blood pressure reaction. From those 156 patients with hypertension, only 21 (13\%) had a systolic brachial-ankle blood pressure difference of greater than $20 \mathrm{~mm} \mathrm{Hg}$, suggesting restenosis. In the patient group without restenosis $(n=245)$, independent risk factors for hypertension were repair with prosthetic material, male sex, a residual brachial-ankle blood pressure difference, and older age at follow-up.

Conclusions: The majority of patients were hypertensive at long-term follow-up after coarctation repair. This is caused by restenosis, defined by a gradient of greater than $20 \mathrm{~mm} \mathrm{Hg}$, in only a few patients. Even in those without prosthetic material or minimal-grade restenosis, there is a substantial incidence of arterial hypertension.

I $\mathrm{n}$ the past, coarctation of the aorta was regarded as a simple lesion cured by means of surgical intervention. However, many recent studies have shown that coarctation of the aorta should be considered a complex cardiovascular syndrome rather than an isolated narrowing at the aortic isthmus. ${ }^{1,2}$

Early elastic fiber fragmentation, fibrosis, and cystic medial necrosis can be found in the walls of the ascending and descending aorta. ${ }^{3,4}$ An increased rate of intracranial aneurysms ${ }^{5}$ suggests that wall abnormalities are not confined to the aorta. They result in an increased stiffness of the aorta $a^{6-10}$ and of the carotid arteries,${ }^{11}$ in a blunted baroreceptor reflex, ${ }^{12,13}$ and in an increased brachial pulse wave velocity. ${ }^{14,15}$

These arteriosclerotic changes are both congenital and acquired. They were found in neonates, ${ }^{4,9}$ even distal to the coarctation site. ${ }^{4}$ On the other hand, aortic stiffness ${ }^{7,10}$ and increased pulse wave velocity ${ }^{14}$ are more profound in patients with late repair and long-standing prestenotic hypertension and in the vessels proximal to the coarctation. 


\section{Abbreviations and Acronyms \\ $\mathrm{ROC}=$ receiver operating characteristic}

As a result, signs of preterm atheromatosis appear early in life and appear as an increased carotid intimal-medial thickness in young adults ${ }^{16,17}$ and children, ${ }^{18}$ as well as a diminished endothelium-dependent and endothelium-independent vasodilatation in the right brachial artery. ${ }^{14,15,18,19}$

All of these pathologic conditions, including restenosis, contribute to an increased cardiovascular morbidity and mortality, such as coronary artery disease, ${ }^{20}$ stroke, heart failure, ruptured aortic and cerebral aneurysms, and sudden cardiac death. ${ }^{21,22}$ It is crucial to detect and treat arterial hypertension early to prevent such a disastrous outcome. ${ }^{20}$ The actual recommendation, residual systolic blood pressure gradient at the coarctation site of greater than $20 \mathrm{~mm}$ $\mathrm{Hg}$ in several studies ${ }^{23}$ or even greater than $30 \mathrm{~mm} \mathrm{Hg}$ in the European Society of Cardiology guidelines, ${ }^{24}$ for removal of restenosis is based on surgical risks established decades ago. Today, new therapeutic options to treat restenosis in the catheter laboratory, such as balloon angioplasty and stent implantation, are highly successful and are associated with a fairly low risk for the patient. However, the contribution of low-grade restenosis to persistent hypertension is unknown. In former studies with a fairly large number of patients, data on the prevalence of arterial hypertension were based on blood pressure data collected through telephone calls to the patients or their family physicians ${ }^{25}$ or from retrospective collection of hospital files. ${ }^{20,22,26,27}$

The aim of this study was to assess the rate of hypertension by means of a fairly complete cross-sectional study of all our patients during long-term follow-up after coarctation repair and to define the contribution of surgical data and current restenosis.

\section{Materials and Methods \\ Study Subjects}

From April 1974 through July 1999, 404 patients born before 1985 underwent surgical repair of isolated aortic coarctation in our institution. The cohort only included those patients who had no additional cardiac defects necessitating surgical or interventional treatment yet. Patients with a persistent arterial duct dissected at surgical coarctation repair were not excluded. Demographic data of the patients are presented in Table 1.

From all 404 eligible patients, 21 were deceased (total mortality, 5.2\%). One of them died at surgical intervention, and 6 died during the postoperative stay in the intensive care unit (perioperative mortality, 1.7\%). Up to now, another 14 patients died at follow-up (late mortality, 3.5\%). All causes of death are shown in Table 2, and Kaplan-Meier curves according to the age at surgical intervention are depicted in Figure E1.

From those 383 patients alive at the study's beginning, 26 moved to remote or unknown areas and could not be contacted. Another 83 patients declined a follow-up examination at our institution. One patient had to be excluded during the study because a lusoric artery (ie, a right subclavian artery arising independently from the aorta after the left subclavian artery) hampered exact precoarctation blood pressure measurement.

The remaining 273 patients ( $71 \%$ of those alive) formed the final study group. Their preoperative data and surgical methods did not differ significantly from those of patients who could not be studied in our standardized way (Table 1 and Figure E2).

The study was approved by the ethics board of the Medical Faculty of the Technische Universität München. Written informed consent was obtained from every patient in the study group.

TABLE 1. Surgical data of primary coarctation repair

\begin{tabular}{|c|c|c|c|c|c|c|c|}
\hline & Patients eligible & $\begin{array}{c}\text { Patients } \\
\text { succumbed }\end{array}$ & $P$ value & Patients alive & $\begin{array}{l}\text { Patients not } \\
\text { studied }\end{array}$ & $P$ value & Patients studied \\
\hline No. of patients & 404 & 21 & & 383 & 110 & & 273 \\
\hline $\operatorname{Sex}(M / F)$ & $266 / 138$ & $13 / 8$ & $.696^{*}$ & $253 / 130$ & $69 / 41$ & $.382^{*}$ & $184 / 89$ \\
\hline Calendar year of operation & 1981 (1974-1999) & 1979 (1974-83) & $.001 \dagger$ & 1982 (1974-1999) & 1982 (1974-1996) & $.778 \dagger$ & 1981 (1974-1999) \\
\hline Age at operation & $9.1(0-56)$ & $13.9(0-43)$ & $.777 \dagger$ & $9.0(0-56)$ & $7.6(0-48)$ & $.140 \dagger$ & $9.7(0-56)$ \\
\hline Type of operation & & & $.416^{*}$ & & & $.649^{*}$ & \\
\hline $\begin{array}{l}\text { Resection and end-to- } \\
\text { end anastomosis }\end{array}$ & 303 & 14 & & 289 & 90 & & 199 \\
\hline $\begin{array}{l}\text { Resection and tube } \\
\text { graft }\end{array}$ & 85 & 6 & & 79 & 17 & & 62 \\
\hline Subclavian flap & 4 & 0 & & 4 & 1 & & 3 \\
\hline Patch plasty & 4 & 0 & & 4 & 0 & & 4 \\
\hline Direct repair & 3 & 1 & & 2 & 1 & & 1 \\
\hline Extra-anatomic bypass & 2 & 0 & & 2 & 0 & & 2 \\
\hline $\begin{array}{l}\text { Subclavian-aortic } \\
\text { anastomosis }\end{array}$ & 3 & 0 & & 3 & 1 & & 2 \\
\hline
\end{tabular}

All data are presented as numbers or medians (ranges). ${ }^{*} \chi^{2}$ Test. †Two-tailed Mann-Whitney $U$ test. 
TABLE 2. Cause of death at/after surgical coarctation repair

\begin{tabular}{|c|c|c|c|c|c|c|}
\hline $\begin{array}{l}\text { Patient } \\
\text { no. }\end{array}$ & Sex & $\begin{array}{c}\text { Age at } \\
\text { operation }\end{array}$ & Surgical technique & $\begin{array}{c}\text { Year of } \\
\text { operation }\end{array}$ & $\begin{array}{c}\text { Survival after } \\
\text { operation }\end{array}$ & Cause of death \\
\hline 1 & $\mathrm{~F}$ & $9 \mathrm{~d}$ & EEA & 1981 & 0 & Intraoperative \\
\hline 3 & $\mathrm{M}$ & $8 \mathrm{~d}$ & EEA & 1980 & $14 \mathrm{~d}$ & Postoperative heart failure \\
\hline 4 & $\mathrm{~F}$ & $8 \mathrm{~d}$ & EEA & 1976 & $16 \mathrm{~d}$ & Postoperative pneumonia \\
\hline 5 & $\mathrm{~F}$ & $3 d$ & EEA & 1976 & $62 \mathrm{~d}$ & Postoperative heart failure \\
\hline 8 & $\mathrm{~F}$ & 32 y & EEA & 1976 & $2.1 \mathrm{y}$ & Unknown \\
\hline 9 & $\mathrm{M}$ & $16 y$ & Direct repair & 1979 & $5.0 \mathrm{y}$ & Heart failure \\
\hline 10 & $\mathrm{M}$ & 31 y & Dacron tube & 1978 & $5.4 \mathrm{y}$ & Unknown \\
\hline 11 & $\mathrm{M}$ & $39 \mathrm{y}$ & Dacron tube & 1979 & $5.5 \mathrm{y}$ & Unknown \\
\hline 12 & $\mathrm{M}$ & $13 y$ & EEA & 1979 & $7.5 \mathrm{y}$ & Ruptured aortic root aneurysm \\
\hline 17 & $\mathrm{~F}$ & $27 \mathrm{y}$ & Dacron tube & 1983 & $16.9 y$ & Cancer, chemotherapy \\
\hline 18 & $\mathrm{M}$ & 31 y & EEA & 1978 & $17.1 \mathrm{y}$ & Heart failure \\
\hline 19 & $\mathrm{M}$ & $43 y$ & Dacron tube & 1974 & $17.1 \mathrm{y}$ & Unknown \\
\hline 20 & $\mathrm{M}$ & $20 \mathrm{y}$ & Dacron tube & 1977 & $17.8 \mathrm{y}$ & Unknown \\
\hline 21 & $\mathrm{~F}$ & $6 y$ & EEA & 1980 & $18.0 \mathrm{y}$ & Unknown \\
\hline
\end{tabular}

$E E A$, Resection and end-to-end anastomosis; Direct repair, direct repair according to Vossschulte; Dacron tube, resection and Dacron tube graft insertion.

\section{Surgical Technique}

The surgical aim of coarctation repair in our institution has been the complete removal of the narrowed aortic region, followed by an end-to-end anastomosis with or without extension into the aortic arch or into the left subclavian artery. The single-stitch technique was used for at least half of the aortic circumference. When it was not possible to mobilize the aorta adequately, a prosthetic tube graft, most often with a diameter of 16 or $18 \mathrm{~mm}$ (range, 12-26 mm), was interposed. This prosthetic tube graft was confined to 62 of 115 patients older than 10 years at the time of surgical intervention (Figure E2). Other surgical methods were rarely performed (Table 1).

\section{Reintervention}

In 29 patients ( $11 \%$ of the study group of 273 patients), reinterventions had been performed. Sixteen of them had repeated operations, another 12 had balloon angioplasty, and in 1 patient a stent was implanted. Five of those 29 patients required a second reintervention ( 3 balloon angioplasties and 2 stents), and 1 patient had a third reintervention (surgical intervention). All reinterventions were related to restenosis. Indication was an invasive blood pressure gradient of greater than $20 \mathrm{~mm} \mathrm{Hg}$ at the coarctation site measured invasively by means of catheterization.

\section{Follow-up Examination}

The follow-up examination was performed solely by 2 of the authors (A.H., S.K.) according to a standardized protocol.
Systolic blood pressure was measured at all 4 limbs by placing a Doppler probe distal to the cuff at the radial or ulnar artery and at the dorsal pedal or anterior tibial artery. A brachial-ankle difference was calculated as the difference between the systolic blood pressure value at the right arm and the higher value of the lower limbs.

Ambulatory blood pressure was measured with an oscillometric device (90207 and 90217 ABP Monitor; Spacelabs Medical, Inc, OSI Systems, Inc, Hawthorne, Calif) at the right upper arm. The appropriate cuff size was chosen according to upper arm circumference. During the daytime (6 AM-8 PM), blood pressure was measured every 20 minutes, and during the nighttime, it was measured every 60 minutes. Mean blood pressure values were calculated from the mean values every hour.

In all but 13 patients (suspected aortic aneurysm in 6 patients, mental retardation in 3 patients, noncooperation in 2 patients, and fibula aplasia and pregnancy in 1 patient each) a symptom-limited exercise test was performed on a bicycle in a sitting position. The World Health Organization protocol was used starting with $25 \mathrm{~W}$ and increasing work load by $25 \mathrm{~W}$ every 2 minutes. Electrocardiography was monitored continuously, and blood pressure was measured manually every 2 minutes.

Doppler echocardiography was performed to measure peak blood flow velocity $\mathrm{V}_{\max }$ at the former coarctation site. The peak instantaneous gradient was calculated from the simplified Bernoulli equation: $4 \cdot\left(V_{\max }\right)^{2}$ (ie, without correction for proximal aortic velocity). Diastolic run-off was defined as a continuous forward flow throughout the whole diastole. No 
acceptable Doppler signals could be achieved in 11 patients, who were only excluded in the analyses concerning Doppler analysis.

\section{Definitions}

Restenosis was defined as a systolic brachial-ankle blood pressure difference of greater than $20 \mathrm{~mm} \mathrm{Hg}{ }^{20}$

Ambulatory arterial hypertension was defined as a 24-hour mean ambulatory systolic blood pressure of greater than $133 \mathrm{~mm}$ $\mathrm{Hg}$ or diastolic blood pressure of greater than $78 \mathrm{~mm} \mathrm{Hg} .^{28}$

Hypertension during exercise was present when the peak systolic blood pressure (in millimeters of mercury) was greater than 2 standard deviations (SDs) more than the age- and work loaddependent reference value ${ }^{29}$ :

$$
\begin{aligned}
\text { Mean } \pm 2 \cdot S D= & 111.2+0.310 \cdot \text { Age }(y) \\
& +0.334 \cdot \text { Work rate }(W) \pm 2 \cdot 17.9
\end{aligned}
$$

A patient was assumed to be normotensive if he or she was without antihypertensive drug treatment, showed no current hypertension at ambulatory blood pressure measurement, and showed no hypertension during exercise. If at least one of these signs was positive, the patient was classified as hypertensive.

\section{Statistical Analysis}

Results are shown as medians (ranges) because most of the data were skewed. Data were analyzed with SPSS 13.0 software (SPSS, Inc, Chicago, Ill).

To find risk factors for hypertension, patients with current restenosis were excluded. The rest were divided into hypertensive and normotensive groups. Comparisons between these groups were performed for categoric variables with $\chi^{2}$ tests and for numeric variables with 2 -sided Mann-Whitney $U$ tests. Afterward, a logistic regression analysis was performed with stepwise conditional entry of variables if the $P$ value was less than .05 .

When numeric variables became significant risk factors, a receiver operating characteristic (ROC) analysis was performed to find thresholds and to demonstrate their discriminative abilities (sensitivity and specificity).

\section{Results}

Sixty-seven patients ( $25 \%$ of the study group) were already receiving antihypertensive drug treatment. A single agent was given to 45 patients ( $28 \beta$-blockers, 12 angiotensinconverting enzyme inhibitors, 3 angiotensin II type 1 receptor antagonists, and $2 \mathrm{Ca}$ antagonists), dual therapy was given to 17 patients, and triple therapy was given to 5 patients. Despite antihypertensive treatment, 6 patients had both systolic and diastolic hypertension at ambulatory blood pressure measurement, another 17 had only systolic hypertension, another 2 had only diastolic hypertension, and only 42 patients $(63 \%$ of the 67 patients with antihypertensive drugs) were normotensive.

Sixty-three patients without drug treatment (23\% of the whole study group of 273 patients) were hypertensive during ambulatory blood pressure measurements. Twenty of them had an increased systolic blood pressure, 15 had an increased diastolic blood pressure, and 28 had both.

Of those without medication and with normal ambulatory blood pressure, $26(10 \%)$ patients had a systolic blood pressure during exercise exceeding 2 standard deviations of reference values. All in all, only 117 (43\%) patients were normotensive.

Of the 156 hypertensive patients, 21 (13\%) had restenosis at the study follow-up examination and were excluded from further analysis, as were the 7 patients with restenosis but without hypertension.

The prevalence of hypertension according to the residual brachial-ankle blood pressure difference is summarized in Table E1.

Of the study group without restenosis $(\mathrm{n}=245), 135$ $(55 \%)$ patients were hypertensive, 56 (24\%) showed an instantaneous peak gradient measured by means of Doppler scanning of greater than $20 \mathrm{~mm} \mathrm{Hg}$, and only 7 (4\%) had a diastolic run-off at Doppler examination.

In the comparative analysis (Table E2) male sex, higher age at surgical intervention, resection with prosthetic tube grafts, current status with prosthetic material, higher age at follow-up (Figure 1), and a higher brachial-ankle difference were all risk factors for hypertension. After entering the statistically most important variable, current state without prosthetic material, into the multiple logistic regression model, age at surgical intervention and type of operation, which were both related to the current state without prosthetic material, were no longer independent risk factors (Table E3).

In a subgroup analysis considering only those patients with end-to-end anastomoses $(\mathrm{n}=199)$, also sex, age at follow-up, and the residual brachial-ankle difference were entered in the regression model, and age at surgical intervention was not significant.

In another subgroup analysis considering only those patients younger than 30 years at follow-up $(n=157)$, the use of prosthetic material, the residual brachial-ankle difference, and age at follow-up outperformed age at surgical intervention, which was again not significant in the multivariable model. Interestingly, only in the older subgroup was sex an independent risk factor.

Even in a third subgroup of patients younger than 30 years and with end-to-end anastomoses $(n=140)$, only the residual brachial-ankle difference was significantly correlated with hypertension, and age at surgical intervention was not $(r=0.053, P=.529)$.

ROC analysis revealed a continuous increase of the risk of hypertension with the brachial-ankle blood pressure difference, as well as with age. It was not able to define cutoff points. Even after reincluding those patients with restenosis according to the common definition, a cutoff point for the brachial-ankle blood pressure difference could not be 


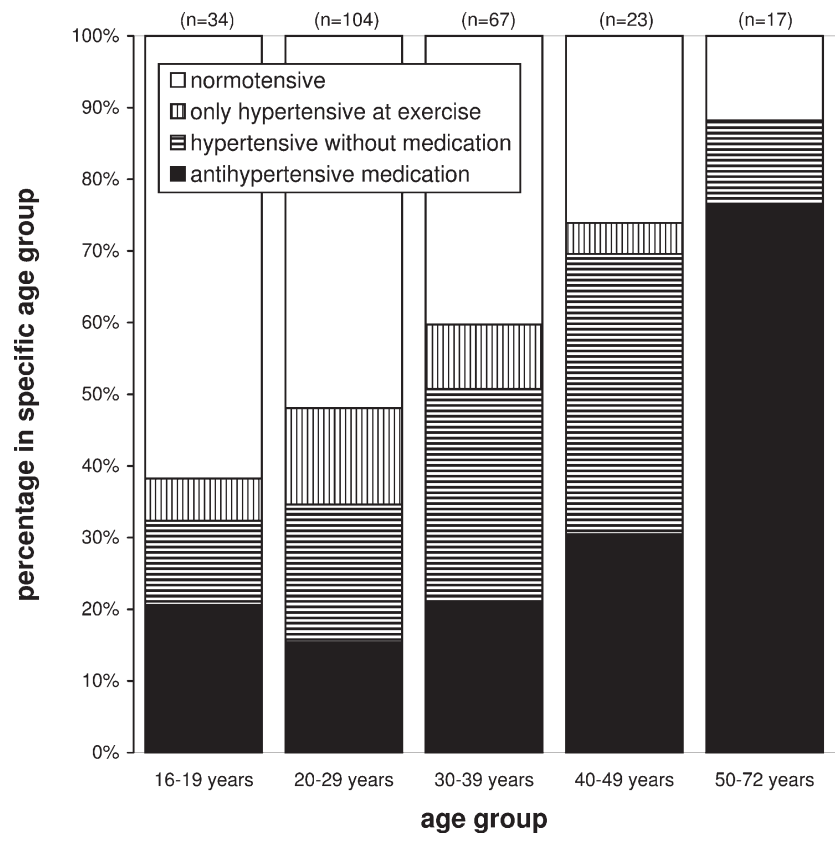

Figure 1. Prevalence of hypertension after coarctation repair.

found. The relationship of the brachial-ankle blood pressure difference and the incidence of hypertension is depicted in Figure 2. A closer look at this plot outlines that only the normal blood pressure situation, with an ankle measurement of at least $10 \mathrm{~mm} \mathrm{Hg}$ greater than the brachial value, together with a repair without prosthetic material revealed the best results on hypertension. But even in these patients with the best results concerning removal of stenosis and probably with the less-impaired compliance at the isthmus, hypertension was found in more than $30 \%$ of the patients (Figure 2).

Finally, another analysis was performed discarding the exercise data and defining hypertension only based on medication and ambulatory blood pressure. Again, the most important risk factors were the prosthetic material (odds ratio, 4.27; 95\% confidence interval $[\mathrm{CI}], 2.12-8.62 ; P<$ .0005 ) and the present age (odds ratio, $1.044 / \mathrm{y} ; 95 \% \mathrm{CI}$, $1.014-1.075 ; P=.004)$. Sex $(P=.064)$ and residual brachial-ankle blood pressure difference $(P=.084)$ failed to be significant, as well as age at surgical intervention $(P=$ $.910)$, type of primary operation $(P=.842)$, reintervention $(P=.609)$, time period after primary operation $(P=.910)$, body weight at follow-up $(P=.163)$, body length at follow-up $(P=.497)$, and body mass index at follow-up ( $P$ $=.219)$.

\section{Discussion}

This study showed, in the form of a rather complete and high-numbered cross-sectional study, that more than half of

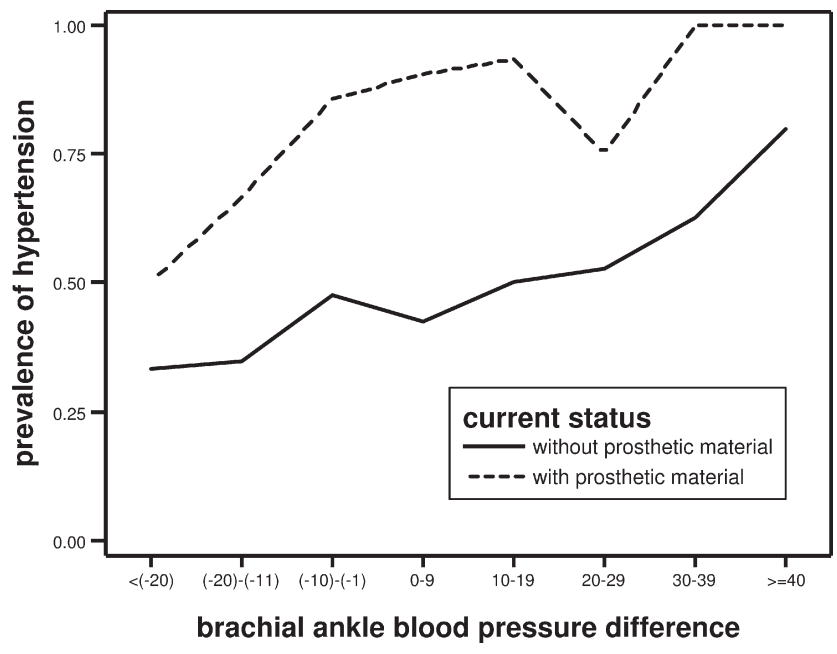

Figure 2. Prevalence of hypertension (antihypertensive drugs, hypertension at ambulatory blood pressure measurement, or hypertension at exercise) according to use of prosthetic material to repair the coarctation and according to the noninvasively measured systolic brachial-ankle blood pressure difference.

the patients after coarctation repair are hypertensive. Because this could be related to age at follow-up, arterial hypertension has to be expected in most of the patients with coarctation in future life. In only a small number of patients, this hypertension could be contributed to restenosis, currently usually defined as a systolic brachial-ankle gradient of greater than $20 \mathrm{~mm} \mathrm{Hg}$.

For those patients without obvious restenosis, the most important risk factor was the use of prosthetic material either at surgical intervention (tube graft or patch) or at catheter intervention (stent). There are 2 explanations for this. First, tube grafts were inserted preferably in patients in whom the aorta could not be mobilized properly to perform an end-to-end anastomosis. These patients were probably those with the most increased aortic stiffness already at the time of surgical intervention. Second, the noncompliant prosthetic material might cause early pulse wave reflection already at the coarctation site and increase pulse wave velocity to the natural reflection area at the bifurcation of the abdominal aorta. Both effects increase systolic blood pressure and enhance the effects of the inborn and acquired aortic stiffness seen in patients with coarctation.

Many previous studies ${ }^{21,30}$ focused on the correlation of hypertension with the age at surgical intervention; however, they did not include current age and current prosthetic material status in their statistical analysis. In our retrospective study group, age at surgical intervention had a great influence on the type of operation and whether prosthetic material was used, which, in the end, 
outperformed all other variables in our statistical analysis. The subgroup analyses including (1) only patients with end-to-end anastomoses, (2) only patients younger than 30 years at follow-up, and (3) only patients who had both criteria, however, underlined that age at surgical intervention has a minor effect on hypertension as opposed to age at follow-up. Nevertheless, age at surgical intervention remains the major risk factor to get prosthetic material at surgical intervention.

Also, arterial hypertension is in substantial part related to low-grade restenosis at the aortic isthmus because minor brachial-ankle differences are another significant contributor, even after excluding patients with gradients of greater than $20 \mathrm{~mm} \mathrm{Hg}$. This is in concordance with a recent study by Vriend and colleages, ${ }^{17}$ who performed a magnetic resonance imaging study on a smaller patient group to assess low-grade restenosis. They excluded high-grade restenosis with a brachial-ankle blood pressure difference of $30 \mathrm{~mm} \mathrm{Hg}$ or greater and still found a significant correlation between repair/diaphragmatic aortic diameter ratio and ambulatory mean daytime systolic blood pressure. Both studies indicate that a new discussion about the indication for restenosis treatment should be initiated.

However, in our study even patients with a, most likely, optimal result at the coarctation site without prosthetic material and without residual gradient were hypertensive at a rate of about $30 \%$. This again outlines the importance of other contributors to hypertension, such as the aforementioned congenital and acquired aortic wall anomalies.

For the clinical management of patients, this study is disappointing because there is no threshold discriminating a clinical relevant residual gradient from a clinical irrelevant gradient. This study showed, by means of ROC analysis, that all thresholds, published either in a guideline ${ }^{24}$ or used in studies, are arbitrary. They are based on old studies weighing surgical risks against risks of arterial hypertension. Today, interventional techniques for treatment of restenosis have tremendously improved. Indeed, balloon angioplasty and stent implantation might treat hypertension with lesser side effects, as well as being cheaper than life-long drug administration. Nevertheless, it still needs to be evaluated how far the improvements of stent implantation on restenosis outweigh the loss of compliance in that aortic segment. This loss of segmental compliance is a matter of concern, which is not only underlined by the worse outcome of prosthetic tube grafts compared with direct anastomosis but also in a recent study by Eicken and associates $^{31}$ showing that only few of the patients become normotensive after stent implantation.

There is not only a future challenge to define new criteria for reintervention but also a challenge for the clinicians to estimate the contribution of a residual narrowing on arterial hypertension. It is difficult and expensive to outweigh findings of restenosis (brachial-ankle blood pressure gradient and repair/diaphragmatic aortic diameter at imaging) with the findings of aortic stiffness (echocardiographic or magnetic resonance imaging stiffening index and pulse wave velocity).

Speculating beyond the aims of the study, perhaps diastolic blood pressure will be one simple key. Prestenotic diastolic blood pressure should be high in restenosis and low in arteriosclerosis with enhanced aortic stiffness. Several Doppler studies have already shown that differentiation between restenosis and enhanced aortic stiffness can be performed by analyzing diastolic flow patterns at the isthmus. ${ }^{32}$ Also, our Doppler data indicate this because many patients without restenosis had an increased peak instantaneous gradient, but only a small number of patients had a diastolic run-off. Therefore the indication for reintervention might be based on a diastolic run-off caused by a diastolic gradient rather than on a certain systolic flow peak converted to a gradient by using the Bernoulli equation.

The value of the exercise hypertension is still in debate. ${ }^{33,34}$ It can occur independently from restenosis. ${ }^{35,36}$ Nevertheless, exercise hypertension is a predictor of hypertension in patients without coarctation. ${ }^{37}$ Therefore there is already discussion about whether and when to treat exercise hypertension. Our study, in which exercise hypertension was defined by reference values and not by values obtained from long-term outcome studies, showed only a small number of patients with isolated exercise hypertension. Therefore physicians will miss only a small number of patients if they do not perform an exercise test but solely rely on ambulatory measurements that, at the moment, have strong evidence for treatment.

In conclusion, this study shows that (1) repair of coarctation should not only remove the stenosis properly but also preserve the compliance of the aorta, (2) a new discussion should be initiated about whether even residual gradients of $20 \mathrm{~mm} \mathrm{Hg}$ or less should be treated because they significantly contribute to hypertension, and (3) even the best morphologic results cannot totally avoid hypertension because coarctation is a systemic vascular disease not limited to the aortic arch.

Finally, this study again outlines the importance of regular follow-up. Even perfect surgical results can only fix the narrowing at the coarctation site. Minor restenosis, loss of distensibility by suture lines or an inserted tube graft, damage from hypertension before surgical intervention, and a congenital systemic vascular disease will cause arterial hypertension and should be expected in the long-term follow-up in most of the patients. Regular screening for 
hypertension and its sequelae is mandatory in all patients after coarctation repair.

\section{Addendum}

In the time interval from the end of this study to the writing of the article, 1 woman from the study group died of a ruptured ascending aortic aneurysm in the third trimester of her second pregnancy. ${ }^{38}$

Thanks to Alexander Gratz for proofreading the manuscript and Dr Michael Hennig, PhD, Institut für Medizinische Statistik und Epidemiologie, Technische Universität München, Germany, for statistical advice.

\section{References}

1. Marx GR. "Repaired" aortic coarctation in adults: not a "simple" congenital heart defect. J Am Coll Cardiol. 2000;35:1003-6.

2. Hager A, Kaemmerer H, Hess J. Comparison of helical CT scanning and MRI in the follow-up of adults with coarctation of the aorta. Chest. 2005; 127:2296.

3. Niwa K, Perloff JK, Bhuta SM, Laks H, Drinkwater DC, Child JS, et al. Structural abnormalities of great arterial walls in congenital heart disease: light and electron microscopic analyses. Circulation. 2001; 103:393-400.

4. Isner JM, Donaldson RF, Fulton D, Bhan I, Payne DD, Cleveland RJ. Cystic medial necrosis in coarctation of the aorta: a potential factor contributing to adverse consequences observed after percutaneous balloon angioplasty of coarctation sites. Circulation. 1987; 75:689-95.

5. Connolly HM, Huston J 3rd, Brown RD Jr, Warnes CA, Ammash NM, Tajik AJ. Intracranial aneurysms in patients with coarctation of the aorta: a prospective magnetic resonance angiographic study of 100 patients. Mayo Clin Proc. 2003;78:1491-9.

6. Ong CM, Canter CE, Gutierrez FR, Sekarski DR, Goldring DR. Increased stiffness and persistent narrowing of the aorta after successful repair of coarctation of the aorta: relationship to left ventricular mass and blood pressure at rest and with exercise. Am Heart J. 1992;123:1594-600.

7. Wessel A, von Samson Himmelstjerna MC, Ruschewski W, Bursch $\mathrm{JH}$. [Effects of age in the correction of isthmus stenosis on postoperative stiffness of the aorta]. Z Kardiol. 1995;84:237-42.

8. Motz R, Waltner-Romen M, Geiger R, Wessel A. [Blood pressure difference between upper arm and thigh, and aortic stiffness in healthy subjects and in patients after coarcectomy]. Klin Padiatr. 2001;213: 290-4.

9. Vogt M, Kuhn A, Baumgartner D, Baumgartner C, Busch R, Kostolny $\mathrm{M}$, et al. Impaired elastic properties of the ascending aorta in newborns before and early after successful coarctation repair: proof of a systemic vascular disease of the prestenotic arteries? Circulation. 2005;111: 3269-73.

10. Brili S, Dernellis J, Aggeli C, Pitsavos C, Hatzos C, Stefanadis C, et al. Aortic elastic properties in patients with repaired coarctation of aorta. Am J Cardiol. 1998;82:1140-3, a10.

11. Vriend JW, de Groot E, Mulder BJ. Limited effect of early repair on carotid arterial wall stiffness in adult post-coarctectomy patients: in response to the article by Heger M, Willfort A, Neunteufl T, Rosenhek R, Gabriel H, Wollenek G, Wimmer M, Maurer G, Baumgartner H. Vascular dysfunction after coarctation repair is related to the age at surgery. Int $J$ Cardiol. 2005;100: 335-6.

12. Beekman RH, Katz BP, Moorehead-Steffens C, Rocchini AP. Altered baroreceptor function in children with systolic hypertension after coarctation repair. Am J Cardiol. 1983;52:112-7.

13. Hanson E, Eriksson BO, Sivertsson R. Baroreceptor reflexes after coarctectomy. Clin Physiol. 1981;1:503-9.
14. de Divitiis M, Pilla C, Kattenhorn M, Zadinello M, Donald A, Leeson $\mathrm{P}$, et al. Vascular dysfunction after repair of coarctation of the aorta: impact of early surgery. Circulation. 2001;104: I165-70.

15. de Divitiis M, Pilla C, Kattenhorn M, Donald A, Zadinello M, Wallace $\mathrm{S}$, et al. Ambulatory blood pressure, left ventricular mass, and conduit artery function late after successful repair of coarctation of the aorta. J Am Coll Cardiol. 2003;41:2259-65.

16. Vriend JJ, De Groot E, Kastelein JJ, Mulder BJ. Carotid and femoral B-mode ultrasound intima-media thickness measurements in adult post-coarctectomy patients. Int Angiol. 2004;23:41-6.

17. Vriend JW, Zwinderman AH, de Groot E, Kastelein JJ, Bouma BJ, Mulder BJ. Predictive value of mild, residual descending aortic narrowing for blood pressure and vascular damage in patients after repair of aortic coarctation. Eur Heart J. 2005;26: 84-90.

18. Meyer AA, Joharchi MS, Kundt G, Schuff-Werner P, Steinhoff G, Kienast W. Predicting the risk of early atherosclerotic disease development in children after repair of aortic coarctation. Eur Heart J. 2005;26:617-22.

19. Gardiner HM, Celermajer DS, Sorensen KE, Georgakopoulos D, Robinson $\mathrm{J}$, Thomas $\mathrm{O}$, et al. Arterial reactivity is significantly impaired in normotensive young adults after successful repair of aortic coarctation in childhood. Circulation. 1994;89:1745-50.

20. Cohen M, Fuster V, Steele PM, Driscoll D, McGoon DC. Coarctation of the aorta. Long-term follow-up and prediction of outcome after surgical correction. Circulation. 1989;80:840-5.

21. Toro-Salazar OH, Steinberger J, Thomas W, Rocchini AP, Carpenter $\mathrm{B}$, Moller JH. Long-term follow-up of patients after coarctation of the aorta repair. Am J Cardiol. 2002;89:541-7.

22. Presbitero P, Demarie D, Villani M, Perinetto EA, Riva G, Orzan F, et al. Long term results (15-30 years) of surgical repair of aortic coarctation. Br Heart J. 1987;57:462-7.

23. Rosenthal E. Stent implantation for aortic coarctation: the treatment of choice in adults? J Am Coll Cardiol. 2001;38:1524-7.

24. Deanfield J, Thaulow E, Warnes C, Webb G, Kolbel F, Hoffman A, et al. Management of grown up congenital heart disease. Eur Heart $J$. 2003;24:1035-84.

25. Forfang K, Rostad H, Sorland S. Coarctation of the aorta. Follow-up of 218 patients operated on after 13 years of age. Acta Med Scand Suppl. 1981;645:15-22.

26. Liberthson RR, Pennington DG, Jacobs ML, Daggett WM. Coarctation of the aorta: review of 234 patients and clarification of management problems. Am J Cardiol. 1979;43:835-40.

27. Maron BJ. Coarctation of the aorta in the adult. Cardiovasc Clin. 1979;10:311-9.

28. Ohkubo T, Imai Y, Tsuji I, Nagai K, Ito S, Satoh H, et al. Reference values for 24-hour ambulatory blood pressure monitoring based on a prognostic criterion: the Ohasama Study. Hypertension. 1998;32: 255-9.

29. Heck H, Rost R, Hollmann W. Normwerte des Blutdrucks bei der Fahrradergometrie. Deutsche Zeitschrift für Sportmedizin. 1984;35: 243-9.

30. Heger M, Willfort A, Neunteufl T, Rosenhek R, Gabriel H, Wollenek $\mathrm{G}$, et al. Vascular dysfunction after coarctation repair is related to the age at surgery. Int J Cardiol. 2005;99:295-9.

31. Eicken A, Pensl U, Sebening W, Hager A, Genz T, Schreiber C, et al. The fate of systemic blood pressure in patients after effectively stented coarctation. Eur Heart J. 2006;27:1100-5.

32. Lim DS, Ralston MA. Echocardiographic indices of Doppler flow patterns compared with MRI or angiographic measurements to detect significant coarctation of the aorta. Echocardiography. 2002; 19:55-60.

33. Swan L, Goyal S, Hsia C, Hechter S, Webb G, Gatzoulis MA. Exercise systolic blood pressures are of questionable value in the assessment of the adult with a previous coarctation repair. Heart. 2003;89:189-92

34. Carano N, Agnetti A, Barone A, Squarcia M, Squarcia U. Exercise test in detecting anomalous behaviour of blood pressure in patients successfully operated on for coarctation of the aorta. Pediatr Med Chir. 1999;21:105-9. 
35. Hauser M, Kuehn A, Wilson N. Abnormal responses for blood pressure in children and adults with surgically corrected aortic coarctation. Cardiol Young. 2000;10:353-7.

36. Gunthard J, Buser PT, Miettunen R, Hagmann A, Wyler F. Effects of morphologic restenosis, defined by MRI after coarctation repair, on blood pressure and arm-leg and Doppler gradients. Angiology. 1996;47:1073-80.
37. Miyai N, Arita M, Miyashita K, Morioka I, Shiraishi T, Nishio I. Blood pressure response to heart rate during exercise test and risk of future hypertension. Hypertension. 2002;39:761-6.

38. Hager A, Kaemmerer H, Hess J. Comment on pregnancy and aortic root growth in the Marfan syndrome. Eur Heart J. 2005;26: 2346.

The Journal of Thoracic and Cardiovascular Surgery Conflict of Interest Policy

To assure fairness to authors submitting work for consideration in The Journal of Thoracic and Cardiovascular Surgery, a mechanism exists for managing conflicts of interest. The editor and each of the section editors complete a "Conflict of Interest" form that identifies any and all relationships with commercial and other academic entities. When the editor has a potential conflict because of a relationship with another entity or author, the editor appoints an alternate editor from among the section editors or editorial board members who assumes the entire responsibility for final decisions on the manuscript in question. The editor does not read the reviews that are submitted nor engage in discussing the manuscript prior to the final decision. When the conflict of interest involves a section editor, a "guest section editor" is appointed who fills the role normally played by the conflicted section editor. All members of the editorial board and reviewers are asked to indicate any conflict of interest when they agree to review a manuscript. 


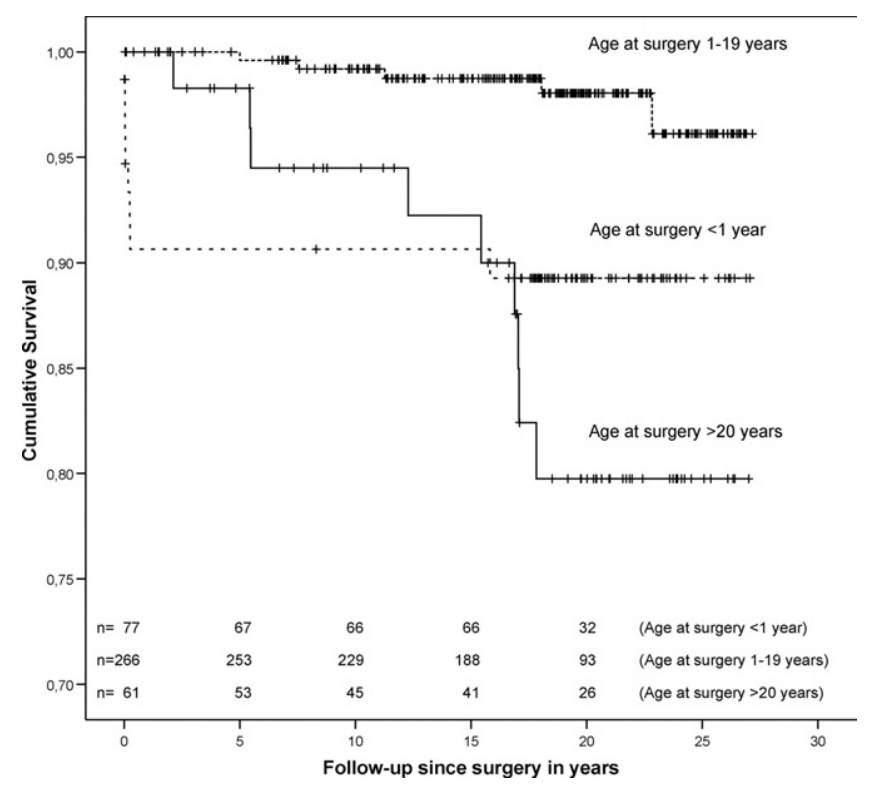

Figure E1. Kaplan-Meier curve of survival according to age at surgical intervention, depicting a prominent early mortality in those patients who underwent coarctation repair at less than 1 year caused probably by the lack of preoperative prostaglandin in those days and depicting a prominent late mortality in patients who underwent surgical intervention at greater than 20 years.

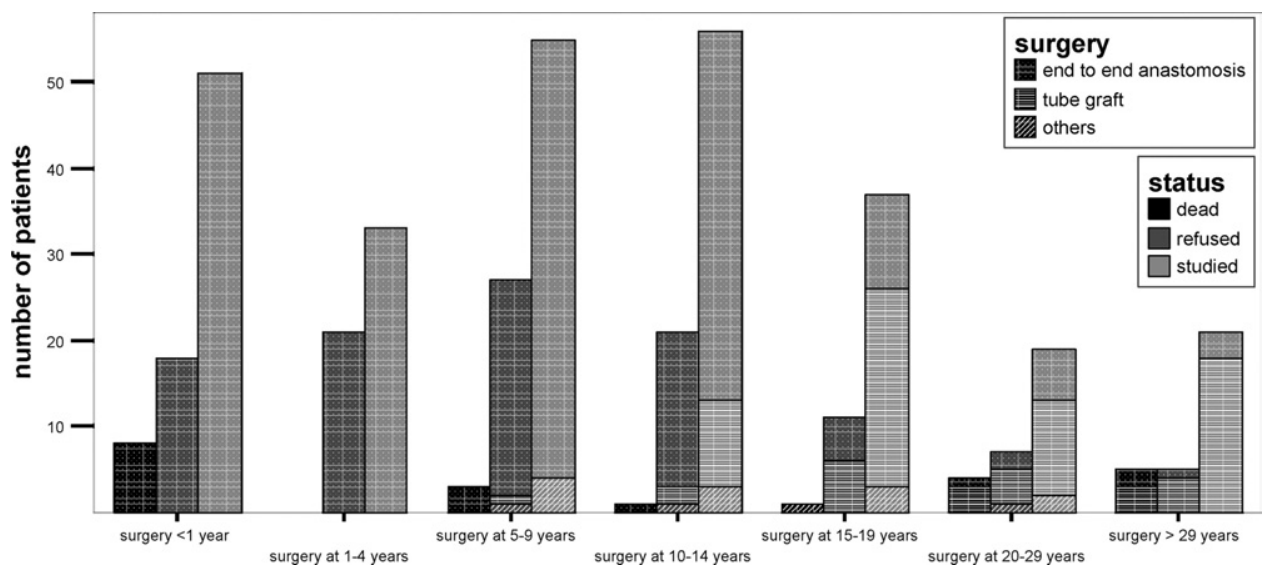

Figure E2. Surgical technique according to age at surgical intervention and study status (dead, not studied, and studied). 
TABLE E1. Prevalence of hypertension according to the residual brachial-ankle blood pressure difference in the long-term follow-up after surgical coarctation repair

\begin{tabular}{|c|c|c|c|}
\hline & \multicolumn{3}{|c|}{ brachial-ankle blood pressure difference } \\
\hline & $<0 \mathrm{~mm} \mathrm{Hg}$ & $0-20 \mathrm{~mm} \mathrm{Hg}$ & $>20 \mathrm{~mm} \mathrm{Hg}$ \\
\hline \multicolumn{4}{|l|}{ No. of patients } \\
\hline With antihypertensive drug treatment & $24(22 \%)$ & $33(24 \%)$ & $10(36 \%)$ \\
\hline Hypertensive without drug treatment & $22(20 \%)$ & $33(24 \%)$ & $8(29 \%)$ \\
\hline Hypertensive only at exercise & $8(7 \%)$ & $15(11 \%)$ & $3(11 \%)$ \\
\hline Normotensive & $56(51 \%)$ & $54(40 \%)$ & $7(25 \%)$ \\
\hline Total & $110(100 \%)$ & $135(100 \%)$ & $28(100 \%)$ \\
\hline
\end{tabular}

TABLE E2. Comparison of patients with hypertension in the long-term follow-up after surgical coarctation repair with those without hypertension

\begin{tabular}{|c|c|c|c|c|}
\hline & Without hypertension & With hypertension & $\chi^{2} / U$ & $P$ value \\
\hline \multicolumn{5}{|l|}{ Demographic data* } \\
\hline Sex (F/M) & $44 / 66$ & $37 / 98$ & 4.343 & .041 \\
\hline \multicolumn{5}{|l|}{ Primary operation } \\
\hline Age at operation & $6.7(0.0-39.1)$ & $13.5(0.0-56.3)$ & 4707 & $<.0005$ \\
\hline Surgical techniquet & $102 / 6 / 2$ & $81 / 47 / 7$ & 34.7 & $<.0005$ \\
\hline Reintervention (yes/no) & $7 / 103$ & $14 / 121$ & 1.242 & .360 \\
\hline Prosthetic material (yes/no) & $9 / 101$ & $56 / 79$ & 34.5 & $<.0005$ \\
\hline \multicolumn{5}{|l|}{ Follow-up } \\
\hline Age & $23.9(16.9-61.5)$ & $31.2(16.8-72.3)$ & 5313 & $<.0005$ \\
\hline Time period after operation & $19.1(2.0-26.9)$ & $19.9(1.4-27.2)$ & 7273 & .782 \\
\hline Body weight & $72(40-115)$ & 73 (44-107) & 6664 & .168 \\
\hline Body length & 172 (152-192) & $175(144-195)$ & 6931 & .370 \\
\hline Body mass index & $23.1(14.2-38.5)$ & $23.7(17.6-37.3)$ & 6461 & .229 \\
\hline brachial-ankle blood pressure difference* & $-5(-45$ to 20$)$ & $0(-40$ to 20$)$ & 7323 & .005 \\
\hline
\end{tabular}

$\chi 2, \chi 2$ test (for categoric variables); $U$, Mann-Whitney $U$ test (for numeric variables). *Patients with restenosis (brachial-ankle blood pressure difference,

$>20 \mathrm{~mm} \mathrm{Hg}$ ) were excluded $(\mathrm{n}=245)$. †Number of patients with end-to-end anastomoses/prosthetic tube grafts/others.

TABLE E3. Risk factors for hypertension after surgical coarctation repair without restenosis in a multivariate logistic regression model

\begin{tabular}{|c|c|c|c|c|}
\hline & Odds ratio & $95 \% \mathrm{Cl}$ & Wald & $P$ value \\
\hline Prosthetic material in situ & 5.995 & $2.573-13.971$ & 13.707 & $<.0005$ \\
\hline Male sex & 2.344 & $1.249-4.402$ & 7.326 & .007 \\
\hline brachial-ankle blood pressure difference & 1.028 & $1.006-1.051$ & 6.344 & .012 \\
\hline Age at follow-up & 1.038 & $1.005-1.071$ & 5.234 & .022 \\
\hline
\end{tabular}

Insignificant variables not entered in the model: age at surgical intervention $(P=.632)$, type of primary operation $(P=.548)$, reintervention $(P=.386)$, time period after primary operation $(P=.632)$, body weight at follow-up $(P=.481)$, body length at follow-up $(P=.203)$, and body mass index at follow-up $(P=.877)$. $\mathrm{Cl}$, Confidence interval. 